\title{
Uma Nota sobre Estimativas de Carga Fiscal e Incidência de ICMS Usando Dados em Painel*
}

\author{
Ricardo Batista Politi ${ }^{\dagger}$, Enlinson Henrique Carvalho de Mattos ${ }^{\ddagger}$
}

\author{
Contents: 1. Introdução; 2. Metodologia; 3. Resultados; 4. Conclusão; A. Cálculo da Carga \\ Fiscal; B. Nota Técnica sobre os Tributos Federais Indiretos. \\ Keywords: Carga Fiscal, Imposto, ICMS, Cesta Básica. \\ JEL Code: H2; H22.
}

Esta nota estima a incidência da Carga Fiscal para 12 bens de consumo no Brasil. A partir de variações de alíquotas no imposto sobre o consumo (ICMS) e preços finais dos bens é aplicada metodologia desenvolvida em Carbonnier (2007) para estimação da incidência neste imposto. São usados dados em painel não balanceado para sete bens da cesta básica do DIEESE em 16 localidades e para outros cinco bens das cestas básicas Estaduais em 11 localidades para o período de julho 1994 a junho de 2008. Os resultados das estimativas mostram que 0 consumidor absorve entre 7\% e 75\% da Carga Fiscal para esses bens e o restante é recolhido pelas firmas. Esse resultado sugere que alterações nas alíquotas do imposto sobre a venda (ICMS), não afetam o consumidor na mesma proporção.

The main purpose of this note is to estimate the tax burden of 12 commodities in Brazil. We collect data of tax rate changes on value added tax (VAT) and tax inclusive prices. Based on this data, econometric methodology is applied based on Carbonnier (2007) to the Brazilian market. Unbalanced panel data includes information about 7 commodities from basic basket food in 16 cities and about 5 other commodities in 11 cities from July 1994 to June 2008. Estimated results suggest that tax burden on consumer relies on between $7 \%$ and $75 \%$ to these commodities and the firms hold a share of the tax burden on VAT. These findings suggest that sales tax rate

\footnotetext{
* Os autores gostariam de agradecer o apoio da FAPESP e aos comentários de Rozane Bezerra de Siqueira, Paulo Picchetti, Cláudio Lucinda, Hugo Borges Jales, Leonardo Baptista Correia e Náercio de Menezes Filho. Os erros remanescentes são de única responsabilidade dos autores.

$\dagger^{\dagger}$ Professor Adjunto da Universidade Federal do ABC (UFABC). E-mail: rbpoliti@gvmail .br

†Professor Associado, Escola de Economia de São Paulo, Fundação Getulio Vargas (EESP/FGV-SP). E-mail: enlinson.mattos@ fgv.br
} 
changes affect commodities prices in different magnitudes (in this case they are under-shifted).

\section{INTRODUÇÃO}

Uma das principais contribuições da teoria econômica à análise da incidência tributária é o reconhecimento que a Carga Fiscal pode onerar outros agentes econômicos além dos responsáveis legais pelo tributo (Kotlikoff e Summers, 1987). ${ }^{1}$ No Brasil, segundo critérios de participação na arrecadação de receita tributária e de participação no orçamento das famílias, o principal tributo indireto com incidência sobre o consumo é o Imposto sobre operações relativas à circulação de mercadorias e serviços de transporte interestadual e intermunicipal e de comunicações (ICMS). ${ }^{2}$ Este trabalho visa mensurar a divisão da Carga Fiscal do ICMS entre firmas e consumidores.

Para mensurar a Carga Fiscal do ICMS no Brasil utiliza-se uma abordagem proposta por Carbonnier (2007). Para implementar essa metodologia é elaborado um Painel de Dados não balanceado com 12 bens. Destes, levantou-se informações a respeito de alterações das alíquotas de ICMS para sete bens da cesta básica elaborada pelo Departamento Intersindical de Estatística e Estudos Socioeconômicos (DIEESE) em 16 cidades para o período de julho de 1994 (Pós Plano Real) a junho de 2008. Os cinco bens restantes podem ser encontrados nas cestas básicas Estaduais em 11 localidades (das 16 acima) para o período de julho de 1994 e dezembro de 2006. Estes bens selecionados são participantes da cesta básica de ao menos cinco Estados diferentes e, portanto, parece razoável considerá-los representativo em âmbito nacional.

A partir de variações nas alíquotas de ICMS e preços finais destes bens, é possível obter estimativas consistentes a respeito da distribuição da Carga Fiscal do imposto sobre as vendas entre firmas e consumidores. Os resultados obtidos mostram que a Carga Fiscal dos consumidores é inferior a 100\% nos 12 bens analisados, sendo que parte significante da incidência do ICMS recai sobre as firmas, com carga estimada entre $93 \%$ e $25 \%$. Esse resultado depende da elasticidade das curvas de oferta e demanda dos bens analisados e pode ser encontrado em mercados oligopolizados, no qual as firmas extraem uma parte maior do excedente do consumidor do que no caso competitivo e por isso absorvem uma parcela maior da Carga Fiscal dos bens (Carbonnier, 2007).

Essa análise é importante para políticas públicas no Brasil, pois sugere que alterações nas alíquotas do imposto sobre a venda (ICMS) dos bens, como reduções de impostos em bens da cesta básica, podem não afetar o consumidor na mesma proporção. A distribuição da Carga Fiscal entre firma e consumidor é analisada em quatro seções. Além desta introdução, a próxima seção traz a metodologia. Por fim, as seções três e quatro apresentam, respectivamente, os resultados estimados e a conclusão do trabalho.

\section{METODOLOGIA}

Segundo Carbonnier (2007), a Carga Fiscal $(c)$ do consumidor pode ser definida como uma função do preço $(p)$ e da alíquota do imposto $(\tau)$. Assim,

$$
c=f(p, \tau)
$$

O preço antes do imposto $(q)$ pode ser representado pela relação $\frac{1}{q}=\frac{1+\tau}{p}$ e mudanças no imposto provocam uma variação de preço ao consumidor de $\frac{d p}{d \tau}$. Assim, o autor define como proxy da carga tributária do consumidor a função:

\footnotetext{
${ }^{1}$ A distribuição da Carga Fiscal entre firmas e consumidores depende da elasticidade da curva de oferta e demanda de mercado em relação ao preço. Para uma discussão detalhada em mercados com diferentes estruturas de concorrência vide Kotlikoff e Summers (1987); e Fullerton e Metcalf (2002, pp. 1823-1828).

${ }^{2}$ O ICMS corresponde à cerca de $30 \%$ da arrecadação em tributos indiretos de acordo com dados da Secretaria da Receita Federal.
} 


$$
f: x \rightarrow x \frac{1+\tau}{1+\tau x}
$$

no qual $x$ assume o valor de

$$
\frac{(1+\tau)}{p} \frac{d e}{d \tau}
$$

De acordo com o modelo, a Carga Fiscal dependerá da variação de preços ao consumidor e da sua relação com a variação de preços ao produtor ou firma. Assim, para cada bem a estimação econométrica do modelo apresenta a seguinte estrutura: ${ }^{3}$

$$
\triangle_{t}(p)=\sum_{t=1} \alpha_{i} \triangle_{t+1-i}(1+\tau)+\beta \triangle_{t j}\left(w_{\text {custos }}\right)+\sum_{i} \gamma_{i} \triangle_{t}\left(t_{\text {trifed }}\right)+\text { Tempot }_{t}+\text { Cidades }_{j}+\varepsilon_{t}
$$

onde: $\triangle$ segue o padrão de um índice:

$$
\triangle_{t}(Z)=\frac{Z_{t}-Z_{t-1}}{Z_{t-1}}
$$

- $t$ designa o período de tempo;

- $j$ designa a localidade;

- $p$ designa a variável preço pós-impostos;

- $w_{\text {custos }}$ designa o índice de custo local (mão de obra - SINAPI);

- $t_{\text {trifed }}$ designam os tributos federais, no caso IPI, COFINS, PIS/PASEP e CPMF;

- $\tau$ designa a alíquota do ICMS no período $t$;

- Tempo representa os efeitos temporais;

- Cidades representam os efeitos da localidade;

a somatória de $\alpha$ designa uma proxy para a variável $x$ que é $x=\frac{(1+\tau)}{p} \frac{d p}{d \tau}$.

Desse modo, por meio do parâmetro $\alpha$ é possível estimar o percentual da Carga Fiscal do consumidor, conforme a relação (Carbonnier, 2007):

Carga Fiscal do consumidor:

$$
(C)=f\left(\sum_{t=1} \alpha_{i}\right)=\left(\sum_{i=1} \alpha_{i}\right)\left(\frac{1+\tau}{1+\tau \sum_{t=1} \alpha_{i}}\right)
$$

Na função (6), a Carga Fiscal do consumidor é estimada a partir da somatória dos coeficientes estimados de transmissão de alíquota de ICMS (somatória até o último coeficiente significante) representado pelo termo $\sum_{i=1} \alpha_{i}$, e considerando a alíquota média (tax inclusive) do ICMS no período $(\tau)$.

Como a variação de preços entre as localidades pode depender dos efeitos permanentes não observados das unidades de análise, uma forma de controlar os efeitos individuais não-observados é por meio de um modelo de efeito fixo (Wooldridge, 2002, Alm et alii, 2009, Besley e Rosen, 1999). A variável 'Cidades' procura considerar os aspectos demográficos, econômicos e jurisdicionais de cada mercado geográfico. Efeitos temporais comuns a todas as localidades, como choques macroeconômicos nos preços,

${ }^{3}$ Para mais detalhes vide Carbonnier (2007, pp. 1225-1226). 
são captados por meio de dummies anuais. Já efeitos temporais sazonais são captados através de dummies trimestrais. $\mathrm{O}$ uso de efeitos fixos e efeitos temporais permitem controlar parcela significativa de eventuais alterações de demanda e custos entre as unidades de observação no decorrer do tempo (Besley e Rosen, 1999).

\subsection{Banco de Dados}

Analisando-se os principais tributos indiretos que incidem sobre o consumo no país, o ICMS, além de sua importância na receita tributária, é o tributo indireto mais adequado para a aplicação do modelo de estimação da Carga Fiscal proposto por Carbonnier (2007). ${ }^{4}$ Pois o elevado número de alterações de alíquotas desse tributo nos âmbitos Estaduais permite obter estimativas robustas a respeito da Carga Fiscal.

Desde julho de 1992 um convênio entre os Estados por meio do CONFAZ (Conselho Nacional de Política Fazendária) permite que estes e o Distrito Federal reduzam a base de cálculo do ICMS nas operações internas para os bens que compõem a cesta básica (Convênio 83/92 CONFAZ, 2008) e posteriormente às próprias alíquotas. Como consequência do Convênio 83 do CONFAZ e de resoluções posteriores, a partir de julho de 1992, muitos Estados mudaram seus regulamentos estaduais de ICMS para definir ou alterar, a composição de sua respectiva cesta básica, suas alíquotas ou mesmo sua base de cálculo (CONFAZ, 2008). Esse movimento nos Estados gerou uma série de alterações nas alíquotas de ICMS dos bens que compõe cada cesta básica estadual. De forma abrangente, os bens da cesta básica se constituem majoritariamente por bens alimentícios. ${ }^{5}$

Os bens analisados foram selecionados com base no número de alterações de alíquotas (ou base de cálculo) de ICMS nos Estados. Esses bens apresentam grande sobreposição com aqueles que compõem a cesta básica calculada pelo DIEESE para 16 capitais estaduais. Entre os bens que compõe as cestas básicas Estaduais, foram excluídos da análise aqueles isentos de cobrança em todos os Estados analisados (caso de hortifrutis em geral), aqueles com alíquotas diferentes de ICMS em menos do que cinco Estados, e aqueles cuja parte representativa das vendas se realiza em estabelecimentos que seguem o Simples Federal (leite e pão) e portanto não sofrem o efeito de alteração de alíquotas do ICMS.

Por esses motivos, os bens selecionados para esta pesquisa foram: açucar, arroz, café, carne bovina, creme dental, feijão, leite em pó, macarrão, manteiga, óleo de soja, sabão e sardinha. É importante citar que os 12 bens alimentícios utilizados nessa pesquisa representam cerca de $20 \%$ dos gastos familiares médios com alimentos no Brasil, de acordo com dados da POF (Pesquisa de Orçamentos Familiares) de 2002-2003, o que ressalta a relevância de compreender a Carga Fiscal do ICMS para os bens dessa pesquisa.

Essas informações estão disponíveis para 14 municípios desde julho de 1994 (Belém, Belo Horizonte, Brasília, Curitiba, Florianópolis, Fortaleza, João Pessoa, Natal, Porto Alegre, Recife, Rio, São Paulo e Vitória) e para uma localidade desde janeiro de 1995 (Goiânia) e uma localidade desde setembro de 1995 (Aracaju). Adicionalmente ao banco de dados do DIEESE, o banco de dados do Índice Nacional de Preços ao Consumidor Amplo (IPCA) do Instituto Brasileiro de Geografia e Estatística (IBGE) fornece informações sobre a variação percentual do preço de cerca de 400 bens em 11 localidades (Brasília,

\footnotetext{
${ }^{4}$ Carbonnier (2007) aplica originalmente esse modelo no mercado francês. Na França, assim como para a maioria dos países da Europa, o imposto sobre o consumo segue o padrão de um IVA (Imposto sobre Valor Agregado), no qual o valor do imposto é calculado sobre o preço da venda, ou seja, trata-se de impostos do tipo tax-exclusive, nos quais a alíquota é expressa como uma fração do preço excluído imposto. Para aplicar essa metodologia no Brasil deve ser considerado que o tributo compõe a sua própria base de cálculo (conhecido como cálculo da alíquota "por dentro"), dado que este é um tributo do tipo tax-inclusive. Para a estimativa dos coeficientes do modelo consideram-se as alíquotas do preço de venda do bem e a alíquota final do ICMS.

${ }^{5}$ A Tabela A.2 no Apêndice aponta os bens mais encontrados nas cestas básicas dos 26 Estados e do Distrito Federal. Além dos bens das cestas básicas Estaduais, outros bens com elevada frequência de alterações de alíquotas são bens não essenciais como fumo, cerveja, refrigerantes, perfumes e cosméticos, ou ainda bens em mercados com histórico de forte regulação como energia elétrica, telecomunicações e combustíveis.
} 
Belém, Belo Horizonte, Curitiba, Fortaleza, Porto Alegre, Recife, Rio de Janeiro, Salvador, São Paulo) a partir de 1989.

O período de análise para os bens da base do DIEESE considera julho de 1994 a junho de 2008 . No caso dos bens da base do IBGE, considerou-se o período de julho de 1994 a junho de 2006, já que os dados dos demais períodos só estão disponíveis para até oito localidades ao invés das 11 localidades originais. Como os preços podem levar alguns meses para responder as alterações de imposto, o uso de dados mensais é o mais indicado para captar as respostas defasadas e estimar a Carga Fiscal, conforme a metodologia proposta (Alm et alii, 2009, Carbonnier, 2007). Nos dois bancos de dados, sobretudo no do IBGE, os dados não estão disponíveis para todas as localidades em todo o período de análise e, portanto, conforme apontado anteriormente trata-se de um Painel Não Balanceado.

Além das alíquotas estaduais de ICMS foram controlados os principais tributos indiretos no Brasil, no caso o Imposto sobre Produtos Industrializados (IPI), a Contribuição para Fins Sociais (COFINS) e a Contribuição para programas de integração social e de formação do patrimônio do servidor público (PIS/PASEP). Na especificação econométrica as três contribuições (COFINS, PIS e CPMF) foram agrupados na variável 'tributos federais' $(T)$, pois essas três contribuições apresentam a mesma alíquota em todo país, com variações apenas temporais. Os valores médios estimados para essa variável para cada bem podem ser conferidas na coluna Tributos Federais da Tabela $1 .{ }^{6}$

Para controlar os custos locais de mão de obra local foi utilizado o indicador SINAPI (Sistema Nacional de Pesquisa de Custos e Índices da Construção Civil - do IBGE). Este indicador traz as variações percentuais no mês dos custos locais de materiais de construção e mão de obra, sendo o único disponível para o caso de 16 localidades. Já o preço final dos bens foi deflacionado pelo IPCA (Índice de Preços ao Consumidor Amplo do IBGE) e dessazonalizado pelo procedimento padrão X-11 ARIMA. A Tabela 1 traz a estatística descritiva das principais variáveis do modelo.

\subsection{Abordagem empírica}

Em relação aos dados, deve-se estar atento a violações das premissas do modelo linear clássico que podem gerar estimadores viesados e/ou não consistentes. Em síntese, temos que identificar se os erros são independentes e identicamente distribuídos (i.d.d.). Sucintamente devem ser analisados quatro fatores. Primeiro, deve-se examinar se a série de preços é estacionária ou não. Em segundo lugar, deve-se identificar se existe autocorrelação dos resíduos, ou seja, se os termos de erros apresentam dependência temporal. Em terceiro, deve investigar se os termos de erro entre as unidades de análise (localidades) apresentam diferentes variâncias entre si, mas são constantes dentro de cada unidade. E por fim, deve-se analisar se os termos de erro de uma unidade estão correlacionados com os termos de erro de outra(s) unidade(s) durante o mesmo período de tempo, a chamada correlação entre os grupos.

O resumo dos resultados se encontra na Tabela A.3 no Apêndice. Em síntese, após deflacionar e dessazonalizar a série de preços das mercadorias, os testes apontam presença de autocorrelação em cinco dos 12 bens analisados, heterocedasticidade entre os grupos em todos os bens, correlação entre as unidades nos 12 bens e ausência de raiz unitária para os dados de preço em todos os produtos. Esse último resultado era esperado, pois o formato dos parâmetros, conforme definido em (6), segue a estrutura de um índice e apresenta efeito estatístico similar a uma transformação de primeira diferença.

Para abordar essas possíveis violações do modelo linear clássico, o método empregado deve abordar essas questões e os testes estatísticos devem ser robustos. Para isso, é empregada a metodologia proposta por Beck e Katz (1995), conhecida como Panel Corrected Standard Error (PCSE). Segundo esta abordagem, como as estimativas de Mínimos Quadrados Ordinários (MQO) dos coeficientes ainda são consistentes, elas devem ser retidas, mas os erros padrões devem ser substituídos por erros padrões corrigidos por painel (Beck e Katz, 1995). Dessa forma, os coeficientes do PCSE são os mesmos coeficientes

\footnotetext{
${ }^{6} \mathrm{~A}$ exclusão desta variável (imposto federal) não altera qualitativamente os resultados. Para detalhes vide nota técnica sobre tributos indiretos no Apêndice B.
} 
Table 1: Estatística Descritiva das Principais Variáveis do Modelo

\begin{tabular}{|c|c|c|c|c|c|c|c|c|}
\hline \multirow{2}{*}{ Produto } & \multirow{2}{*}{$\begin{array}{c}\text { ICMS } \\
\text { (média) }\end{array}$} & \multicolumn{5}{|c|}{ Evolução da aliquota de ICMS (média anual) } & \multirow{2}{*}{ Preço } & \multirow{2}{*}{$\begin{array}{l}\text { Tributos } \\
\text { Federais }\end{array}$} \\
\hline & & 1994 & 1997 & 2000 & 2003 & 2006 & & \\
\hline \multirow[t]{2}{*}{ Açúcar } & 0,098 & 0,133 & 0,101 & 0,090 & 0,094 & 0,083 & 1,43 & 0,066 \\
\hline & $(0,052)$ & $(0,050)$ & $(0,053)$ & $(0,052)$ & $(0,047)$ & $(0,047)$ & $(0,351)$ & $(0,020)$ \\
\hline \multirow[t]{2}{*}{ Arroz } & 0,097 & 0,121 & 0,103 & 0,088 & 0,096 & 0,091 & 1,86 & 0,041 \\
\hline & $(0,041)$ & $(0,042)$ & $(0,042)$ & $(0,042)$ & $(0,035)$ & $(0,042)$ & $(0,407)$ & $(0,029)$ \\
\hline \multirow[t]{2}{*}{ Café } & 0,103 & 0,141 & 0,104 & 0,088 & 0,101 & 0,094 & 11,35 & 0,066 \\
\hline & $(0,045)$ & $(0,042)$ & $(0,047)$ & $(0,043)$ & $(0,039)$ & $(0,042)$ & $(3,349)$ & $(0,020)$ \\
\hline \multirow[t]{2}{*}{ Carne bovina } & 0,094 & 0,110 & 0,097 & 0,084 & 0,098 & 0,085 & 9,51 & 0,066 \\
\hline & $(0,049)$ & $(0,049)$ & $(0,046)$ & $(0,049)$ & $(0,048)$ & $(0,052)$ & $(1,256)$ & $(0,020)$ \\
\hline \multirow[t]{2}{*}{ Creme dental } & 0,172 & 0,175 & 0,175 & 0,170 & 0,170 & 0,164 & 1,91 & 0,086 \\
\hline & $(0,020)$ & $(0,005)$ & $(0,005)$ & $(0,017)$ & $(0,017)$ & $(0,022)$ & $(0,224)$ & $(0,039)$ \\
\hline \multirow[t]{2}{*}{ Feijão } & 0,091 & 0,121 & 0,098 & 0,083 & 0,085 & 0,080 & 2,83 & 0,041 \\
\hline & $(0,045)$ & $(0,042)$ & $(0,048)$ & $(0,047)$ & $(0,037)$ & $(0,042)$ & $(0,841)$ & $(0,029)$ \\
\hline \multirow[t]{2}{*}{ Leite em pó } & 0,146 & 0,172 & 0,155 & 0,145 & 0,137 & 0,111 & 16,95 & 0,066 \\
\hline & $(0,073)$ & $(0,019)$ & $(0,041)$ & $(0,058)$ & $(0,051)$ & $(0,061)$ & $(2,795)$ & $(0,020)$ \\
\hline \multirow[t]{2}{*}{ Macarrão } & 0,128 & 0,143 & 0,138 & 0,118 & 0,125 & 0,103 & 4,20 & 0,066 \\
\hline & $(0,065)$ & $(0,033)$ & $(0,039)$ & $(0,052)$ & $(0,040)$ & $(0,063)$ & $(0,829)$ & $(0,020)$ \\
\hline \multirow[t]{2}{*}{ Manteiga } & 0,129 & 0,154 & 0,140 & 0,134 & 0,121 & 0,107 & 14,98 & 0,066 \\
\hline & $(0,046)$ & $(0,032)$ & $(0,044)$ & $(0,043)$ & $(0,045)$ & $(0,049)$ & $(2,614)$ & $(0,020)$ \\
\hline \multirow[t]{2}{*}{ Óleo de soja } & 0,109 & 0,125 & 0,101 & 0,097 & 0,096 & 0,148 & 2,49 & 0,066 \\
\hline & $(0,045)$ & $(0,049)$ & $(0,047)$ & $(0,038)$ & $(0,035)$ & $(0,038)$ & $(0,537)$ & $(0,020)$ \\
\hline \multirow[t]{2}{*}{ Sabão } & 0,145 & 0,166 & 0,151 & 0,142 & 0,133 & 0,129 & 1,71 & 0,066 \\
\hline & $(0,020)$ & $(0,024)$ & $(0,042)$ & $(0,042)$ & $(0,046)$ & $(0,044)$ & $(0,277)$ & $(0,020)$ \\
\hline \multirow[t]{2}{*}{ Sardinha } & 0,137 & 0,158 & 0,140 & 0,134 & 0,130 & 0,125 & 14,47 & 0,066 \\
\hline & $(0,069)$ & $(0,024)$ & $(0,046)$ & $(0,058)$ & $(0,052)$ & $(0,056)$ & $(2,212)$ & $(0,020)$ \\
\hline
\end{tabular}

Fonte: elaborado a partir de DIEESE (2008), IBGE (2008), Receita Federal (2009) e regulamentos estaduais do ICMS (CONFAZ, 2008).

Em parêntesis: desvio padrão.

ICMS e Tributos Federais em alíquotas centesimais.

Preço em RS deflacionado com base em junho de 2008 e dessazonalizado.

Custo para Base DIEESE apresenta média geral 0,0069 e desvio padrão de 0,013.

Custo para Base IBGE apresenta média geral 0,0103 e desvio padrão de 0,0156. 
do MQO ou do Painel de Efeito Fixo (já que foram usadas dummies para controlar os efeitos locais), o que muda é o cálculo do erro padrão. Para estimar o erro padrão robusto é empregada uma correção por meio da matriz de correlação contemporânea, tratando dessa forma o problema da correlação entre as unidades. ${ }^{7}$ As propriedades assintóticas dessa matriz convergem à medida que o período de observações aumenta (à medida que $T$ tende ao infinito), de modo que essa especificação é consistente para casos no qual o período de análise é bastante superior ao número de unidades (Estados) analisado (Greene, 2003). A autocorrelação é corrigida pelo método de Prais-Winsten (ver também Alm et alii, 2009) para os cinco bens que rejeitaram a hipótese de não correlação (feijão, leite em pó, macarrão, manteiga, óleo de soja).

Já o número de defasagens selecionado (seis) para a variável do coeficiente de transmissão do imposto foi obtido por meio de testes AIC/BIC (Akaike information criterion/Schwartz ou Bayesian information criterion) que indicam a especificação mais adequada segundo os critérios de aderência ou ajustamento do modelo.

\section{RESULTADOS}

A fim de se obter a estimativa da carga tributária do consumidor deve-se considerar a somatória dos coeficientes de transmissão de imposto até o último período significante (Carbonnier, 2007). Os resultados com a variável de transmissão de imposto até a última defasagem significante estão na Tabela 2. ${ }^{8}$ A Carga Fiscal estimada para o consumidor nos 12 bens ficou entre $7 \%$ (creme dental) e $75 \%$ (óleo de soja). A Carga Fiscal média estimada para o consumidor entre os 12 bens pesquisados é de $38 \%$. Em seis dos bens pesquisados a carga tributária estimada para o consumidor é bem próxima da média, com resultados entre $29 \%$ (manteiga) e $53 \%$ (feijão). A Carga Fiscal da firma pode ser obtida diretamente da Carga Fiscal do consumidor, sendo o resultado a diferença entre $100 \%$ e a carga estimada do consumidor. Assim, a Carga Fiscal da firma é estimada entre 93\% (creme dental) e 25\% (óleo de soja). A Figura 1 representa graficamente a Carga Fiscal estimada para o consumidor.

A Tabela 2 mostra que, mesmo se tratando de 12 bens essenciais, os bens que apresentam menor possibilidade de substituição e, portanto, devem contar com demanda menos elástica, são aqueles bens com maior valor estimado de Carga Fiscal para o consumidor, caso de açúcar, arroz, feijão, macarrão e óleo de soja. Por outro lado, alguns bens com maior possibilidade de substituição, e, portanto demanda mais elástica, como carne bovina, manteiga e sardinha em lata apresentam menor valor estimado de Carga Fiscal ao consumidor. ${ }^{9}$

Nesse contexto é relevante testar se a Carga Fiscal é estatisticamente diferente de $100 \%$. Como a função para estimar a carga prevê a soma do parâmetro de transmissão do imposto até a última defasagem significativa, elaborou-se o teste $t$ para testar a hipótese nula de que a somatória dos $\beta$ 's até a última defasagem significativa é igual a um. ${ }^{10}$ É esse o resultado exibido na Tabela 2 , na terceira linha de baixo para cima. Nesse caso, identifica-se que para oito dos 12 bens analisados, com exceção de creme dental, feijão, leite em pó e macarrão, pode-se rejeitar a hipótese nula de que a carga tributária do consumidor seja igual a $100 \%$ com ao menos $10 \%$ de significância.

Por fim, é importante levantar a hipótese se alterações de preços de bens considerados substitutos ou complementares decorrentes ou não de mudanças tributárias podem provocar efeito substituição e

\footnotetext{
${ }^{7}$ Vide Beck e Katz (1995, pp. 638).

${ }^{8}$ A descrição detalhada de como obter a estimativa da Carga Fiscal a partir dos coeficientes da regressão encontra-se no Apêndice A.

${ }^{9}$ Em relação a café é difícil explicar o resultado negativo na terceira defasagem, mas a estimativa com uma única defasagem de, aproximadamente $48 \%$ de Carga Fiscal, é mais próxima da média da pesquisa e parece mais razoável.

${ }^{10}$ Neste procedimento foi realizado o teste conjunto de Wald para testar se a somatória dos coeficientes $\left(\sum \beta_{I C M S}=1\right)$ até o último valor estimado significante é equivalente a um. Essa abordagem soma os respectivos desvios padrões e considera a matriz de variância/covariância dos coeficientes.
} 
Table 2: Coeficientes do Modelo e Estimativa da Carga Fiscal do Consumidor

\begin{tabular}{|c|c|c|c|c|c|c|}
\hline & Açúcar & Arroz & Café & Carne & Creme dental & Feijão \\
\hline \multirow[t]{2}{*}{$\mathrm{ICMS}_{t}$} & $0,605^{* * *}$ & $0,493^{* *}$ & $0,401^{* * *}$ & 0,079 & $-0,263$ & $0,509^{*}$ \\
\hline & $(0,189)$ & $(0,198)$ & $(0,137)$ & $(0,123)$ & $(0,258)$ & $(0,307)$ \\
\hline \multirow[t]{2}{*}{$\mathrm{ICMS}_{t-1}$} & $-0,009$ & 0,162 & 0,105 & $-0,172$ & $-0,040$ & 0,181 \\
\hline & $(0,247)$ & $(0,216)$ & $(0,141)$ & $(0,132)$ & $(0,258)$ & $(0,318)$ \\
\hline \multirow[t]{2}{*}{$\mathrm{ICMS}_{t-2}$} & 0,188 & 0,135 & $-0,428^{* * *}$ & $0,236^{*}$ & 0,037 & 0,451 \\
\hline & $(0,249)$ & $(0,207)$ & $(0,140)$ & $(0,131)$ & $(0,257)$ & $(0,317)$ \\
\hline \multirow[t]{2}{*}{ ICMS $_{t-3}$} & $-0,080$ & 0,094 & $-0,045$ & $-0,049$ & 0,146 & $-0,082$ \\
\hline & $(0,245)$ & $(0,216)$ & $(0,139)$ & $(0,133)$ & $(0,258)$ & $(0,311)$ \\
\hline \multirow[t]{2}{*}{ ICMS $_{t-4}$} & $-0,072$ & $-0,101$ & 0,085 & $-0,087$ & $-0,214$ & 0,090 \\
\hline & $(0,252)$ & $(0,218)$ & $(0,139)$ & $(0,131)$ & $(0,181)$ & $(0,309)$ \\
\hline \multirow[t]{2}{*}{ ICMS $_{t-5}$} & 0,058 & $-0,095$ & $-0,070$ & $-0,117$ & $0,392^{* *}$ & $-0,016$ \\
\hline & $(0,252)$ & $(0,218)$ & $(0,139)$ & $(0,131)$ & $(0,181)$ & $(0,325)$ \\
\hline \multirow[t]{2}{*}{ ICMS $_{t-6}$} & $-0,074$ & 0,032 & 0,111 & $-0,164$ & $-0,008$ & $-0,053$ \\
\hline & $(0,229)$ & $(0,212)$ & $(0,136)$ & $(0,128)$ & $(0,242)$ & $(0,315)$ \\
\hline \multirow[t]{2}{*}{ Trib. Federais } & $-0,034$ & 0,018 & $0,264^{* * *}$ & $0,089^{* * *}$ & $-0,464$ & 0,005 \\
\hline & $(0,083)$ & $(0,073)$ & $(0,043)$ & $(0,032)$ & $(0,403)$ & $(0,088)$ \\
\hline \multirow[t]{2}{*}{ Custos } & $0,445^{* * *}$ & $0,310^{* * *}$ & $0,350^{* * *}$ & $0,375^{* * *}$ & $-0,107^{*}$ & $0,248^{* *}$ \\
\hline & $(0,077)$ & $(0,067)$ & $(0,041)$ & $(0,029)$ & $(0,059)$ & $(0,125)$ \\
\hline$\tau$ (alíquota md) & $10,9 \%$ & $10,7 \%$ & $11,5 \%$ & $10,9 \%$ & $20,1 \%$ & $10,0 \%$ \\
\hline \multirow{2}{*}{$\begin{array}{l}\sum \beta_{I C M S}=1 \\
p \text {-valor }\end{array}$} & rejeita & rejeita & rejeita & rejeita & não rejeita & não rejeita \\
\hline & $0,037^{* *}$ & $0,011^{* *}$ & $0,000^{* * *}$ & $0,000^{* * *}$ & 0.115 & 0,1030 \\
\hline \multirow[t]{2}{*}{$\operatorname{Carga}^{1}(C)$} & $63,0 \%$ & $51,9 \%$ & $8,6 \%$ & $15,5 \%$ & $6,9 \%$ & $53,3 \%$ \\
\hline & Leite em Pó & Macarrão & Manteiga & Óleo & Sabão & Sardinha \\
\hline \multirow[t]{2}{*}{$\mathrm{ICMS}_{t}$} & $-0,020$ & 0,078 & 0,210 & 0,086 & 0,158 & 0,031 \\
\hline & $(0,304)$ & $(0,098)$ & $(0,195)$ & $(0,114)$ & $(0,131)$ & $(0,155)$ \\
\hline \multirow[t]{2}{*}{ ICMS $_{t-1}$} & $-0,036$ & $0,190^{*}$ & $-0,028$ & 0,147 & $-0,025$ & $-0,072$ \\
\hline & $(0,304)$ & $(0,099)$ & $(0,200)$ & $(0,171)$ & $(0,132)$ & $(0,155)$ \\
\hline \multirow[t]{2}{*}{$\mathrm{ICMS}_{t-2}$} & $-0,368$ & 0,020 & $-0,100$ & 0,027 & $0,244^{*}$ & 0,013 \\
\hline & $(0,307)$ & $(0,099)$ & $(0,202)$ & $(0,176)$ & $(0,131)$ & $(0,156)$ \\
\hline \multirow[t]{2}{*}{$\mathrm{ICMS}_{t-3}$} & 0,163 & $-0,059$ & $-0,196$ & 0,114 & $-0,095$ & 0,148 \\
\hline & $(0,314)$ & $(0,097)$ & $(0,196)$ & $(0,175)$ & $(0,111)$ & $(0,157)$ \\
\hline \multirow[t]{2}{*}{$\mathrm{ICMS}_{t-4}$} & $0,632^{* *}$ & 0,007 & $0,377^{*}$ & $-0,000$ & $-0,074$ & $0,310^{*}$ \\
\hline & $(0,284)$ & $(0,096)$ & $(0,195)$ & $(0,177)$ & $(0,110)$ & $(0,177)$ \\
\hline \multirow[t]{2}{*}{$\mathrm{ICMS}_{t-5}$} & $-0,087$ & 0,014 & 0,213 & 0,057 & $-0,049$ & 0,154 \\
\hline & $(0,290)$ & $(0,097)$ & $(0,196)$ & $(0,177)$ & $(0,116)$ & $(0,180)$ \\
\hline \multirow[t]{2}{*}{ ICMS $_{t-6}$} & $-0,049$ & $0,230^{* *}$ & 0,005 & $0,297^{*}$ & $-0,013$ & $-0,372^{* *}$ \\
\hline & $(0,293)$ & $(0,113)$ & $(0,191)$ & $(0,168)$ & $(0,116)$ & $(0,178)$ \\
\hline \multirow[t]{2}{*}{ Trib. Federais } & $-2,905$ & $-0,099$ & 0,054 & 0,067 & 0,251 & $-0,592$ \\
\hline & $(1,980)$ & $(0,518)$ & $(0,039)$ & $(0,075)$ & $(0,360)$ & $(0,601)$ \\
\hline \multirow[t]{2}{*}{ Custos } & $-0,120$ & $-0,005$ & $0,382^{* * *}$ & $-0,017$ & 0,004 & $-0,046$ \\
\hline & $(0,355)$ & $(0,033)$ & $(0,038)$ & $(0,020)$ & $(0,030)$ & $(0,079)$ \\
\hline$\tau$ (alíquota md) & $15,1 \%$ & $14,1 \%$ & $14,8 \%$ & $12,2 \%$ & $16,5 \%$ & $14,8 \%$ \\
\hline$\sum \beta_{I C M S}=1$ & não rejeita & rejeita & rejeita & não rejeita & rejeita & rejeita \\
\hline$p$-valor & 0,4160 & $0,089^{*}$ & $0.061^{*}$ & 0,618 & $0,007^{* * *}$ & $0,073^{*}$ \\
\hline $\operatorname{Carga}^{1}(C)$ & $40,4 \%$ & $51,4 \%$ & $29,2 \%$ & $74,9 \%$ & $41,3 \%$ & $23,5 \%$ \\
\hline
\end{tabular}

Obs: números em parêntesis indicam valores da estatística $t$ robusta;

* nível de significância de 10\%; ** nível de significância de 5\%; *** nível de significância de 1\%;

Todas as regressões incluem variáveis de controle Tempo e Cidade.

$\tau$ alíquota média (cálculo "por dentro") é usada na equação (6).

${ }^{1}$ Para descrição do cálculo da Carga vide Apêndice A. 
Figure 1: Carga Fiscal Estimada ao Consumidor por Bens

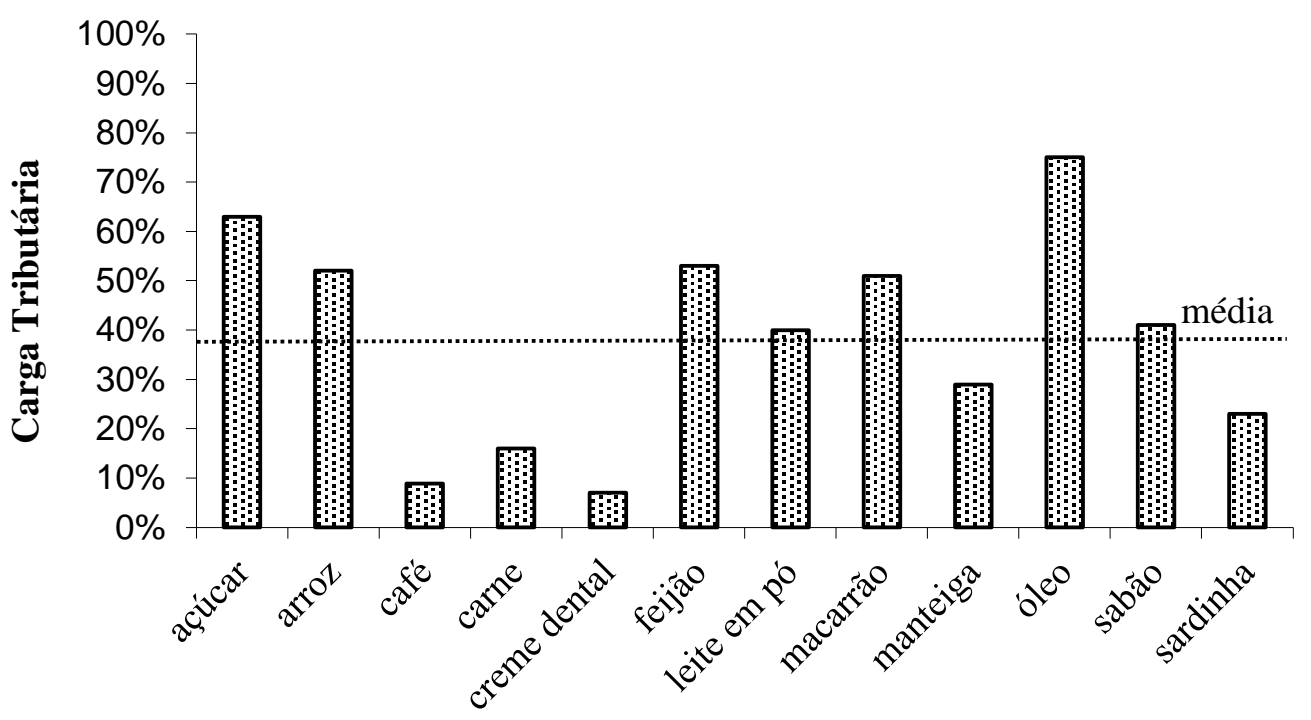

Obs: período de julho de 1994 a dezembro de 2006 para creme dental, leite em pó, macarrão, sabão e sardinha; demais bens: julho de 1994 a junho de 2008.

alteração nos preços dos bens sob análise e afetar o resultado dessa pesquisa. Argumenta-se aqui que, os bens analisados compõem as cestas básicas de vários Estados e foram classificados dessa maneira devido o seu baixo grau de substituição, de forma que os bens são pouco elásticos em relação aos preços dos outros bens se comparados com outros bens da cesta de consumo das famílias. Trabalhos com metodologia semelhante também ignoram esta questão (Alm et alii, 2009, Besley e Rosen, 1999).

\section{CONCLUSÃO}

Com base na metodologia desenvolvida por Carbonnier (2007) este trabalho apresenta estimativas da Carga Fiscal para 12 bens no mercado brasileiro. Os resultados encontrados demonstram que em pelo menos nove dos 12 bens analisados a parcela do consumidor na distribuição da Carga Fiscal está entre 23\% e $75 \%$. A estimativa da distribuição da Carga Fiscal entre firmas e consumidores complementa a literatura de incidência tributária no país, onde os trabalhos mais relevantes analisam as alíquotas efetivas dos tributos (Sampaio de Souza, 1996, Siqueira et alii, 2001). Ainda, a Carga Fiscal do consumidor nos bens analisados é inferior a 100\%, resultado também encontrado por Carbonnier (2007), e em sintonia com um dos resultados previstos em modelo de incidência tributária para oligopólios.

Esses resultados apresentam importantes implicações para políticas públicas. Alterações das alíquotas de impostos sobre a venda, como é o caso do ICMS, podem não atingir o consumidor com a mesma magnitude da alteração da alíquota. Foram encontradas fortes evidências empíricas de que esse é o caso na maioria dos bens analisados. Tais evidências lançam dúvidas quanto ao impacto de medidas de desoneração de tributos indiretos para o bem estar dos consumidores. Mais importante, a análise dos efeitos distributivos de políticas públicas também vai além da questão da distribuição da Carga Fiscal. Envolve a avaliação do uso da receita tributária e os seus impactos no bem estar dos agentes econômicos (Fullerton e Metcalf, 2002). Estudos adicionais poderiam ser realizados com o propósito de aprofundar 
a discussão a respeito da estrutura de concorrência de cada mercado e mesmo para outros bens com bastante importância no orçamento das famílias e também no volume de arrecadação tributária, tais como combustíveis, energia elétrica e telecomunicações.

\section{BIBLIOGRAPHY}

Alm, J., Sennoga, E., \& Skidmore, M. (2009). Perfect competition, urbanization, and tax incidence in the retail gasoline market. Economic Inquiry, 47:118-134.

Baum, C. (2001). Residual diagnostics for cross-section time series regression models. The Stata Journal, 1:101-104.

Beck, N. \& Katz, J. N. (1995). What to do (and not to do) with time-series cross-section data. American Political Journal Review, 89:634-647.

Besley, T. J. \& Rosen, H. S. (1999). Sales taxes and prices: An empirical analysis. National Tax Journal, 52:157-177.

Carbonnier, C. (2007). Who pays sales taxes? Evidence from French VAT reforms, 1987-1999. Journal of Public Economics, 91:1219-1229.

DIEESE (2008). Departamento Intersindical de Estatística e Estudos Socioeconômicos. Disponível em: (http://www.dieese.org.br/rel/rac/cesta.xml). Vários acessos.

Fullerton, D. \& Metcalf, G. E. (2002). Tax incidence. In Auerbach, A. \& Feldstein, M., editors, Handbook of Public Economics, chapter 29, pages 1788-872. Elsevier Publishing Co., Amsterdam, Holanda.

Greene, W. (2003). Econometric Analysis. Prentice Hall, Upper Saddle River, New Jersey, $6^{\text {th }}$ edition.

IBGE (2008). Instituto Brasileiro de Geografia e Estatística. Disponível em: (http://www.ibge.gov . $\mathrm{br} /$ home/). Vários acessos.

Kotlikoff, L. J. \& Summers, L. H. (1987). Tax incidence. In Auerbach, A. \& Feldstein, M., editors, Handbook of Public Economics, volume 2, pages 1043-1092. Elsevier Publishing Co., Amsterdam, Holanda.

Maddala, G. S. \& Wu, S. A. (1999). Comparative study of unit root tests with panel data and new simple test. Oxford Bulletin of Economics and Statistics, 61:631-652.

Sampaio de Souza, M. C. (1996). Tributação indireta no Brasil: Eficiência versus equidade. Revista Brasileira de Economia, 50:3-20.

Siqueira, R., Nogueira, J., \& Souza, E. (2001). A incidência final dos impostos indiretos no Brasil: Efeitos da tributação de insumos. Revista Brasileira de Economia, 55:513-544.

Wooldridge, J. M. (2002). Econometric Analysis of Cross Section and Panel Data. MIT Press, Cambridge, MA, 1a. edition.

Zee, H. (1995). Value added tax. In Parthasarathi, S., editor, Tax Policy Handbook. International Monetary Fund, Washington, DC. 


\section{A. CÁLCULO DA CARGA FISCAL}

O cálculo da Carga Fiscal do Consumidor $(C)$ segue (6):

$$
(C)=\left(\sum_{i=1} I C M S_{i}\right)\left(\frac{1+\tau}{1+\tau \sum_{i=1} I C M S_{i}}\right)
$$

no qual, $\sum I C M S$ representa a somatória até o último coeficiente significante.

Dessa forma, seja o cálculo de $(C)$ para 'sabão':

De acordo com os resultados da Tabela 2, o último (e nesse caso também o único) coeficiente significante é o da segunda defasagem. Assim, o termo $\sum I C M S$ para sabão é obtido pela soma dos coeficientes estimados de transmissão de ICMS até a última defasagem significativa:

$$
\sum I C M S=(0,158)+(-0,025)+(0,244)=0,3768
$$

Já o termo $\tau$ representa a alíquota média (cálculo "por dentro") do tributo para o bem em todas as localidades durante o período analisado. No caso de sabão, $\tau=0,165$.

Assim, a Carga Fiscal do bem é resultado do produto:

$$
(C)=(0,3768)\left(\frac{1+0,165}{1+(0,165(0,3768))}\right)
$$

Resolvendo:

$$
(C)=0,413
$$

Portanto, Carga Fiscal do consumidor para sabão equivale a 41,3\%. 


\section{B. NOTA TÉCNICA SOBRE OS TRIBUTOS FEDERAIS INDIRETOS}

Em relação aos tributos federais IPI, COFINS, PIS ou ainda a CPMF, a incidência é a mesma em todas as unidades estaduais, pois se tratam de tributos com abrangência nacional. $O$ único bem dessa pesquisa em que há incidência de IPI é o açúcar refinado, mas não houve alteração de alíquota desse tributo para o período analisado. Para estimar as alíquotas de COFINS e PIS foram adotadas duas premissas. Até dezembro de 2002 para o PIS e fevereiro de 2004 para a COFINS estimou-se a alíquota acumulada dessas contribuições assumindo-se quatro etapas na cadeia produtiva de todos os bens. Depois dessas datas, assumiram-se as alíquotas do regime de valor agregado. Foram assumidas quatro etapas no processo produtivo e a adição de valor agregado de $50 \%$ entre as transações (três), de modo que uma alíquota nominal de 2,65\% (caso da alíquota de COFINS e PIS/PASEP em 1998, por exemplo) resulte em uma alíquota estimada de 5,59\%. O mesmo mecanismo foi adotado para a CPMF. As alterações de alíquotas da COFINS, do PIS/PASEP e da CPMF, bem como as isenções foram consideradas e estão detalhadas na Tabela A.1 deste Apêndice.

Ainda em relação ao ICMS, algumas falhas de incidência tributárias distribuídas ao longo da cadeia produtiva, como isenções relativas a créditos tributários acumulados em alguma etapa intermediária de produção, podem não ser recuperados em etapas seguintes da produção e isso pode aumentar a base de cálculo do imposto, fazendo com que a base fiscal do ICMS seja superior ao montante agregado em etapas anteriores, aumentando a alíquota efetiva para os bens na etapa final (vide Zee, 1995). Para este trabalho são consideradas as alíquotas nominais finais do mercado interno. Não são considerados os créditos fiscais, os subsídios bem como as alíquotas de ICMS para bens importados. Neste caso é dificil determinar o sinal de viés de nossa estimação, pois isto depende da correlação desta variável omitida (alíquota efetiva) com a variável de interesse. Se supusermos que as eventuais isenções estão positivamente correlacionadas com o movimento das alíquotas nominais teríamos um viés para cima do coeficiente estimado da Carga Fiscal. Por outro lado, se estas isenções estiverem negativamente correlacionadas com o movimento das alíquotas, nossas estimativas estão subestimando o parâmetro verdadeiro da firma. A hipótese mais provável parece ser a primeira opção, pois movimentos de isenção na cadeia tendem a ser acompanhado por aumentos na alíquota final ao consumidor (ver Zee (1995, p. 93)). Se acreditarmos nessa hipótese, nossas estimativas podem ser consideradas conservadoras em relação à Carga Fiscal do consumidor.

Por fim, os bens selecionados para essa pesquisa, sobretudo os alimentícios, podem apresentar muitas oscilações de preços. Para obter estimativas consistentes é importante controlar as variações de oferta e de demanda desses bens. Já para verificar se eventuais choques na oferta dos bens estão sendo adequadamente controlados pela variável temporal, realizou-se uma especificação adicional com a variável de controle preço pago ao produtor sobre a matéria-prima em sete (bens da base do DIEESE) dos bens analisados. O preço pago ao produtor é isento de impostos e por isso essa variável pode ser usada como controle sem necessidade de alterar a especificação. Com essa variável de controle na especificação, os resultados de uma forma geral se mantêm e não apresentam diferença significativa. Adicionalmente, apesar de limitados pela base de dados, usamos duas outras especificações para reforçar os resultados. Na primeira incluímos o preço dos bens de forma contemporânea e que podem ser considerados substitutos ou complementares aos bens em questão. Vale notar que esta especificação apresenta problemas típicos de endogeneidade. Na segunda consideramos a estimação de um VAR simples com todos os bens agrícolas considerando as mesmas defasagens do modelo padrão. Os resultados reforçam qualitativamente nossas estimativas do modelo padrão e podem ser disponibilizados mediante solicitação aos autores. 
Tabela A.1: Resumo das alterações dos principais Tributos Indiretos Federais

\begin{tabular}{|c|c|c|c|}
\hline Tributo & Data & Alíquota & Marco Jurídico \\
\hline & $25 / 05 / 1982$ & $2 \%$ & Decreto-lei 1.940, de 25.5.1982 \\
\hline & 01/02/1999 & $3 \%$ & Lei 9.718, de 27.11.1998 \\
\hline Cofins & $01 / 10 / 2002$ & $10.3 \%^{1}$ & Medida Provisória ${ }^{0}$ 41/2002 \\
\hline \multirow[t]{4}{*}{ (antigo Finsocial) } & $01 / 02 / 2004$ & $7,60 \%$ & Lei 10.833 , de 29.12 .2003 \\
\hline & $26 / 07 / 2004$ & $0 \%^{2}$ & Lei $10.925 / 2004$ \\
\hline & $16 / 06 / 2007$ & $0 \%^{3}$ & Lei $\mathrm{n}^{0} 11.488$, de 15.06 .2007 \\
\hline & $26 / 09 / 2008$ & $0 \%{ }^{4}$ & Lei $\mathrm{n}^{0} 11.787$, de 25.09 .2008 \\
\hline \multirow[t]{2}{*}{ PIS/PASEP } & antes & $0,65 \%$ & Leis 7.859 , de 25.10 .1989 \\
\hline & $01 / 12 / 2002$ & $1,65 \%$ & Lei 10.637 , de 30.12 .2002 \\
\hline IPMF & $1 / 1 / 1994$ até $31 / 12 / 1994$ & $0,25 \%$ & Lei Complementar 77, de 13.7.1993 \\
\hline \multirow[t]{3}{*}{$\mathrm{CPMF}^{*}$} & 23/01/1997 até 24/02/1998 & $0,20 \%$ & Emenda Constitucional 12, de 15.8.1996 \\
\hline & $17 / 06 / 2000$ até $18 / 03 / 2001$ & $0,30 \%$ & Emenda Constitucional 21 de 18.3.1999 \\
\hline & até $31 / 12 / 2007$ & $0,38 \%$ & \\
\hline
\end{tabular}

Fonte: Receita Federal (2009).

*Obs: A contribuição foi extinta em 23 de janeiro de 1999, tendo sido substituida pela IOF até o reestabelecimento em 17 de junho de 1999.

${ }^{1}$ Para preparações para higiene bucal ou dentária (Pis passou a 2,30\%).

${ }^{2}$ Para arroz, feijão e farinha de mandioca.

${ }^{3}$ Para leite pasteurizado.

${ }^{4}$ Para farinha e pão.

Tabela A.2: Frequência dos Bens nas Cestas Básicas Estaduais

\begin{tabular}{clc}
\hline Grupo & \multicolumn{1}{c}{ Bens } & Presença \\
\hline 1 & $\begin{array}{l}\text { Açúcar, arroz, café, carne bovina, farinha de mandioca e de trigo, } \\
\text { feijão, leite pasteurizado ou UHT, manteiga ou margarina, óleo de } \\
\text { soja, sal }\end{array}$ & mais de 20 Estados \\
2 & $\begin{array}{l}\text { Biscoito, carne de ave, leite em pó, macarrão, pão, sabão, sardinha } \\
\text { em lata, vinagre }\end{array}$ & entre 10 e 20 Estados \\
3 & $\begin{array}{l}\text { Creme dental, desodorante, escova dental, linguiça, mortadela, } \\
\text { ovo, queijos, sabão, sabonete }\end{array}$ & menos de 10 Estados \\
\hline
\end{tabular}

Fonte: elaborado a partir de regulamentos estaduais de ICMS (CONFAZ, 2008). 
Tabela A.3: Testes Estatísticos

$H_{0}$ : Assume ausência de erros esféricos

\begin{tabular}{|c|c|c|c|c|}
\hline Bens & Raiz Unitária ${ }^{1}$ & Não Autocorrelação ${ }^{2}$ & Homocedasticidade $^{3}$ & $\begin{array}{l}\text { Não correlação } \\
\text { entre unidades }\end{array}$ \\
\hline \multirow{2}{*}{ Açúcar } & $(0,0000)$ & $(0,3287)$ & $(0,0000)$ & $(0,0000)$ \\
\hline & rejeita $H_{0}$ & não rejeita $H_{0}$ & rejeita $H_{0}$ & rejeita $H_{0}$ \\
\hline \multirow{2}{*}{ Arroz } & $(0,0000)$ & $(0,9944)$ & $(0,0000)$ & $(0,0000)$ \\
\hline & rejeita $H_{0}$ & não rejeita $H_{0}$ & rejeita $H_{0}$ & rejeita $H_{0}$ \\
\hline \multirow{2}{*}{ Café } & $(0,0000)$ & $(0,5772)$ & $(0,0000)$ & $(0,0000)$ \\
\hline & rejeita $H_{0}$ & não rejeita $H_{0}$ & rejeita $H_{0}$ & rejeita $H_{0}$ \\
\hline \multirow{2}{*}{ Carne } & $(0,0000)$ & $(0,1136)$ & $(0,0000)$ & matriz \\
\hline & rejeita $H_{0}$ & não rejeita $H_{0}$ & rejeita $H_{0}$ & singular \\
\hline \multirow{2}{*}{ Creme dental } & $(0,0000)$ & $(0,3354)$ & $(0,0000)$ & matriz \\
\hline & rejeita $H_{0}$ & não rejeita $H_{0}$ & rejeita $H_{0}$ & singular \\
\hline \multirow{2}{*}{ Feijão } & $(0,0000)$ & $(0,0000)$ & $(0,0000)$ & 0,000 \\
\hline & rejeita $H_{0}$ & rejeita $H_{0}$ & rejeita $H_{0}$ & rejeita $H_{0}$ \\
\hline \multirow{2}{*}{ Leite em pó } & $(0,0000)$ & $(0,0002)$ & $(0,0000)$ & matriz \\
\hline & rejeita $H_{0}$ & rejeita $H_{0}$ & rejeita $H_{0}$ & singular \\
\hline \multirow{2}{*}{ Macarrão } & $(0,0000)$ & $(0,0017)$ & $(0,0000)$ & matriz \\
\hline & rejeita $H_{0}$ & rejeita $H_{0}$ & rejeita $H_{0}$ & singular \\
\hline \multirow{2}{*}{ Manteiga } & $(0,0000)$ & $(0,0085)$ & $(0,0000)$ & $(0,0000)$ \\
\hline & rejeita $H_{0}$ & rejeita $H_{0}$ & rejeita $H_{0}$ & rejeita $H_{0}$ \\
\hline \multirow{2}{*}{ Óleo } & $(0,0000)$ & $(0,0368)$ & $(0,0000)$ & $(0,0000)$ \\
\hline & rejeita $H_{0}$ & rejeita $H_{0}$ & rejeita $H_{0}$ & rejeita $H_{0}$ \\
\hline \multirow{2}{*}{ Sabão } & $(0,0000)$ & $(0,4742)$ & $(0,0000)$ & matriz \\
\hline & rejeita $H_{0}$ & não rejeita $H_{0}$ & rejeita $H_{0}$ & singular \\
\hline \multirow{2}{*}{ Sardinha } & $(0,0000)$ & $(0,2097)$ & $(0,0000)$ & matriz \\
\hline & rejeita $H_{0}$ & não rejeita $H_{0}$ & rejeita $H_{0}$ & singular \\
\hline
\end{tabular}

Obs: Em parêntesis resultados do $p$-valor.

1 Teste de Fischer (Phillip-Perron) com coeficiente para Raiz Unitária em Painel (Maddala e Wu, 1999).

2 Teste de Wooldridge (2002) para Autocorrelação em Painel.

3 Teste de Wald modificado (Baum, 2001).

4 Teste LM de Breusch Pagan (Baum, 2001).

Estatística $F$ para autocorrelação e chi-quadrada para heterocedasticidade e correlação entre grupos. 